\title{
Long-term evaluation of the rise in legal age-of-sale of cigarettes from 16 to 18 in England: a trend analysis
}

\author{
Emma Beard ${ }^{1 *}$, Jamie Brown ${ }^{1}$, Sarah Jackson ${ }^{1}$, Robert West ${ }^{1}$, Will Anderson ${ }^{2}$, Deborah Arnott $^{2}$ and Lion Shahab ${ }^{1}$
}

\begin{abstract}
Objective: To assess the long-term impact of the increase in age-of-sale of cigarettes from 16 to 18 in England in October 2007.

Methods: Data were collected between November 2006 and September 2018 on 252,601 participants taking part in a nationally representative survey of adults aged 16+ in England, the Smoking Toolkit Study (STS). We assessed the impact of the introduction of the increase in age-of-sale on prevalence of ever smoking, current smoking, and quit attempts, among 16-17 year olds compared with 18-24 year olds.
\end{abstract}

Results: Following the increase in age-of-sale, there was a declining trend in ever smoking that was greater among 16-17 year olds than 18-24 year olds (OR 0.990 versus OR 0.993; $p=0.019$ ). Data on current smoking were insensitive to detect a difference between the age groups in a step-level change or change in trend following the increase in age-ofsale (Bayes factors (BFs) 0.75 and 2.10). Data on quit attempts were also insensitive to detect a change in trend (BF 0.71), and despite a greater step-level decline among those aged 16-17 (OR 0.311 versus OR $0.547, p=0.025$ ), quit attempts remained higher among those aged 16-17. Secondary analysis indicated that post-policy change, trends in current and ever smoking were linear for 16-17 year olds but quadratic for 18-24 year olds (slowing decline).

Conclusion: There is some evidence from an assessment of long-term trends in the Smoking Toolkit Study that the increase in legal age-of-sale of cigarettes in England was associated with a greater long-term decline in ever smoking among those aged 16-17 compared with those aged 18-24.

Keywords: Smoking, Youth, Age-of-sale, Tobacco

\section{Introduction}

A majority of smokers in the UK report that they began smoking before the age of 18 , with the mean age of onset of regular smoking being 16 years [1]. In England, the legal age-of-sale was increased from 16 to 18 years on 1 October 2007 [2]. This does not apply to consumption, with tobacco products only confiscated by the police for those under 16 years of age. There have been

\footnotetext{
* Correspondence: e.beard@ucl.ac.uk

'Department of Behavioural Science and Health, University College London, 1-19 Torrington Place, London, UK

Full list of author information is available at the end of the article
}

calls in the UK to raise the legal age-of-sale further to 21 [3], the hope being that this will not only prevent uptake but reduce teenagers' access to tobacco products purchased by their peers. Other jurisdictions have already increased the legal age-of-sale to 21 , and there is evidence for its effectiveness $[4,5]$. This paper considers the impact of the increase in age-of-sale restrictions in England from 16 to 18 on long-term trends in current smoking, ever smoking (as a measure of uptake), and attempts to quit among young people. Such findings will help to inform policymakers as to the possible effectiveness of increasing the legal age-of-sale further [3]. 
Two studies have formally assessed the short-term effects of the age-of-sale increase in England, showing that there was an immediate fall in youth smoking rates $[2,6]$. However, these evaluations had several limitations. In the study by Fidler and West [2], a simple prepost comparison was made, with an assessment of moderation effects by age. Thus, it was not possible to account for underlying secular trends, seasonal effects, or the introduction of other population-level tobacco control polices. This sort of analysis also precludes the ability to assess non-linear trends triggered by the introduction of the increase in age-of-sale. Although Millett et al. [6] looked at changes over time and accounted for secular trends, their analysis focused solely on 11 to 15 year olds meaning it was not possible to test for differences between age groups for whom buying cigarettes did or did not remain legal. They also did not adjust for population-level policies or seasonality, and the annual nature of data collection meant it was not possible to do a more fine grained analysis in the months immediately after the rise in age-of-sale.

Descriptive and quasi-experimental evidence from outside of the UK also suggests that short- to long-term effects are likely to arise [7]. In Sweden, compliance, assessed through test purchasing, increased over an 8year period following the introduction of the minimum age of purchase [8]. These findings were supported in a survey of 19 European Union countries, which showed that laws prohibiting the sales of tobacco to minors were associated with lower perceived obtainability of cigarettes [9]. In a state-level study in the USA, cigarette control laws were shown to be effective in reducing the rate of cigarettes sold by merchants to minors [10], while after the tobacco sales ban to minors in 1995 in Finland, there was a permanent decline in purchases from commercial sources among those aged 14-16 [11]. A study in Canada assessed the impact of 'hypothetical' changes in the legal age-of-sale on smoking prevalence, finding that both daily and non-daily smoking was much higher in those older than the minimum age-of-sale [12].

This study aimed to conduct the first formal analysis of the long-term impact on youth smoking of the increase in age-of-sale of cigarettes from 16 to 18 years in England in October 2007. Monthly data were used from the Smoking Toolkit Study (STS) (www.smokinginengland.info), a population-level survey of adults age 16+ in England, between November 2006 and September 2018. We assessed the differential impact of the introduction of the increase in age-of-sale on prevalence of current smoking, ever smoking, and quit attempts among 16-17 year olds and 18-24 year olds while adjusting for underlying trends, seasonality, and population-level policies introduced during that period. Both linear and non-linear trends were modelled. Previous studies have generally focused on uptake of smoking or smoking prevalence. However, population level time series analyses provide preliminary evidence that the rise in age-of-sale may also have had an impact on quitting activity, at least in the short term $[13,14]$.

\section{Methods \\ Design}

Data were used from the STS between November 2006 and September 2018. The STS is a monthly survey of a representative sample of the population in England aged $16+$, which collects data on smoking patterns among smokers and recent ex-smokers [15]. The STS uses a random location sampling design, with initial random selection of grouped output areas (containing 300 households), stratified by ACORN (socio-demographic) characteristics (http://www.caci.co.uk/acron/acornmap.asp) and region. Interviewers then choose which houses within these areas are most likely to fulfil their quotas and conduct face-to-face computer-assisted interviews with one member per household. The STS sample appears to be representative of the population in England, having a similar socio-demographic composition to other large national surveys, such as the Health Survey for England and retail sales data $[15,16]$.

\section{Measures}

\section{Outcomes}

Participants were asked: 'Which of the following best applies to you? a) I smoke cigarettes (including handrolled) every day; b) I smoke cigarettes (including handrolled), but not every day; c) I do not smoke cigarettes at all, but I do smoke tobacco of some kind (e.g. pipe or cigar); d) I have stopped smoking completely in the last year; e) I stopped smoking completely more than a year ago; f) I have never been a smoker (i.e. smoked for a year or more)'. Current smokers were defined as those who reported a, b, or c and ever smokers as those who reported a, b, c, d, or e.

Past-year smokers (a, b, c, or d) were also asked: 'How many serious attempts to stop smoking have you made in the last 12 months? By serious attempt I mean you decided that you would try to make sure you never smoked again. Please include any attempt that you are currently making and please include any successful attempt made within the last year'. Past-year quit attempts were coded 1 for participants who reported having made at least 1 serious quit attempt and 0 for those who did not report any serious quit attempts in the last 12 months.

\section{Seasonality, trends, and intervention effects}

We included two time variables to account for underlying secular trends (coded $1 \ldots n$, where $n$ is the total 
number of waves) and seasonality (with months coded 0 through 11). An additional variable reflected the preand post-implementation periods in order to identify step-level changes in prevalence (coded 0 before the increase in age-of-sale and 1 after). Finally, we included a variable to reflect the change in trend following the increase in age-of-sale (coded 0 before the intervention and $1 \ldots m$ after the intervention, where $m$ is the number of waves after the increase in age-of-sale).

\section{Covariates}

Participants were asked for other socio-demographic information (including age, gender, and social grade). Social grade was measured using the British National Readership Survey (NRS) Social-Grade Classification Tool, which on the basis of the occupation of the chief income earner in the household categorises people as $\mathrm{ABC} 1$ (this included managerial, professional, and intermediate occupations) versus C2DE (this includes small employers, and ownaccount workers, lower supervisory and technical occupations, and semi-routine and routine occupations, never workers, and long-term unemployed) [17].

Monthly tobacco control mass media expenditure (in million £) was obtained from Public Health England. The following tobacco control policies were also adjusted for using a temporary pulse effect, whereby a dummy variable was coded 0 before and after the policy was introduced and 1 during the month the policy was introduced: (1) the introduction of a ban in enclosed public spaces in July 2007 [18], (2) pictorial health warnings on product packaging introduced in October 2008 [19], (3) licencing of NRT for harm reduction in December 2009 [20], (4) point-of-sale ban introduced in England in April 2012 [21], (5) the move in commissioning of stop smoking services to local authorities in April 2013 [22], and (6) the publication of NICE guidance on harm reduction in June 2013 [23]. Sensitivity analyses were also run which modelled the two policies occurring closest in time to the increase in age-of-sale, the introduction of a ban in enclosed public spaces and the pictorial health warnings on product packaging, as longterm step-level changes.

Finally, sensitivity analyses adjusted for self-reported average weekly spend on tobacco. To assess expenditure on smoking, current smokers were asked: 'On average about how much per week do you think you spend on cigarettes or tobacco?' and to report the number of cigarettes they smoke per day. Smokers' average cost of smoking (in $£$ /week) was derived from the following liberal assumptions for upper estimates of plausible levels of consumption and expenditure per week: (1) smokers smoke a maximum of 560 cigarettes per week, (2) spending does not exceed $£ 280$ per week, and (3) single cigarettes cost between $£ 0.05$ and $£ 1$ [24].
These covariates were chosen a priori and included in the pre-registered analysis plan. Decisions were based on previous research showing their association with smoking uptake and quitting activity. For example, the introduction of a ban in enclosed public spaces in July 2007 was found to be associated with a temporary increase in the percentage of smokers attempting to stop [18], while pictorial health warnings on product packaging introduced in October 2008 have been found to promote smoking cessation and may reduce uptake $[19,25]$. An evaluation of the partial (i.e. supermarket) tobacco point-of-sale display ban introduced in England in April 2012 found evidence for a decline in smoking prevalence [21]. Licencing of nicotine replacement therapy for use in harm reduction, and higher expenditure on tobacco control mass media have been found to be associated with the success of quit attempts [26]. Time series analyses have also shown that cuts on tobacco mass media expenditure have been associated with a reduction in use of smoking cessation support [27, 28]. Smoking prevalence is highest among those from disadvantaged backgrounds, and these smokers appear less likely to succeed in qutting than those from more advantaged groups $[29,30]$. There are also gender differences in smoking, with men tending to use tobacco products at higher rates than women [31]. Finally, tax increases over the study period have resulted in the rise in cost of smoking [32], and although smokers often adjust their behaviour to account for these, tax increases have been shown to be a cost-effective intervention for reducing smoking prevalence by promoting quitting and reducing uptake [33, 34].

\section{Analysis}

Questions on the cost of cigarettes were only collected between October 2007 and June 2009 and then from August 2010 onwards. Missing values for these periods were imputed using Kalman Smoothing for univariate time series data [35].

Data were analysed in $\mathrm{R}$ studio. The analysis plan was pre-registered on the Open Science Framework (https:// osf.io/3wgmn/). First, unweighted and weighted sociodemographic and smoking descriptive statistics were calculated. The STS uses rim (marginal) weighting to match the sample to the population in England on the dimensions of age, social grade, region, housing tenure (bought on a mortgage, owned outright, rented from local authority, and rented from private landlord), ethnicity, and working status (working or not working) within sex.

\section{Primary analysis-difference-in-differences}

Generalised Additive Models (GAMs) were used for the difference-in-differences (DID) segmented analysis at the individual non-aggregated level. These allow the fitting 
of seasonal smoothing terms and thus seasonality to be taken into account. For the primary analysis, we compared 16-17 year olds with 18-24 year olds. The unadjusted DID model was specified as:

$$
\begin{aligned}
y_{t}= & \beta_{0}+\beta_{1} \text { age }+\beta_{2} \text { trend }+\beta_{3} \text { level }_{t}+\beta_{4} \text { slope } \\
& +\beta_{5} \text { level }{ }_{t} \times \text { age }+\beta_{6} \text { slope } \times \text { age }+e_{t}
\end{aligned}
$$

$y_{t}$ reflects the dependent variable at time $t$ (i.e. prevalence), $\beta$ reflects the various coefficients, and $e_{t}$ is the error at time $t$. Level distinguishes the periods pre- and post-implementation of the increase in age-of-sale, coded 0 before the increase and 1 after. Trend accounts for secular trends with a variable coded $1 \ldots n$, where $n$ is the number of months in the study period. Slope reflects the slope after the introduction of the increase in age-ofsale coded 0 before the introduction and $1 \ldots m$ after, where $m$ is the number of months in the study period after the increase in age-of-sale. Additional models were run adjusting for gender, social grade $(A B C 1$ versus C2DE), tobacco control mass media spend, and population-level policies occurring during the study period. For the primary analysis, a linear underlying and post-implementation trend was assumed.

\section{Secondary analyses-trend analysis}

Secondary analyses then assessed whether polynomial regression with terms up to an order of 3 (i.e. quadratic trend and cubic trend model) for the post-implementation trend provided a better fit for 16-17 and 18-24 year olds. This was then repeated with segmented regression models. These allow relationships that are linear but segmented, namely represented by at least two lines connected at 'breakpoints'. Breakpoints were determined using an iterative procedure, whereby models with different positions of maximally one breakpoint were compared using the Akaike information criterion (AIC). The best fitting model was chosen as the model with lowest AIC. Generally, the simplest model is chosen where the difference in AIC (delta) is $<2$.

Bayes factors (BFs) were derived for the primary non-significant findings using an online calculator to disentangle whether there was evidence for the null hypothesis of no effect $(\mathrm{BF}<1 / 3)$, the alternative hypothesis $(\mathrm{BF}>3)$ or whether data were insensitive (e.g. large standard error or lack of power) [36]. A half-normal distribution was assumed with an effect size for a step-level change of $\mathrm{OR}=1.36$ and for the change in slope of $\mathrm{OR}=1.001$. These were derived from a study assessing the short-term effects of increase of age-of-sale from 16 to 18 [2].

STrengthening the Reporting of Observational studies in Epidemiology (STROBE) guidelines were followed throughout [37].

\section{Sensitivity analysis}

Sensitivity analyses repeated the primary analysis with the older age group split into 18-21 year olds and 2224 year olds. This is important given the argument that the increase in age-of-sale should be increased further to $21[3]$.

\section{Amendments to the analysis plan}

An amendment was made to the analysis plan in May 2019. As the underlying trend did not differ significantly as a function of age group, an interaction term between the underlying trend and age was not included in the final model to preserve power. The underlying trend before the increase in age-of-sale was thus assumed to be the same among 16-17 year olds and 18-24 year olds. The fitted trend was found to fit the pre-implementation data well for both age groups.

An additional amendment was made in June 2019 to the analysis plan following calculation of Bayes factors which suggested that the data were insensitive to detect a difference among 16-17 year olds and 18-24 year olds in a step-level change and change in trend. An additional age group (25+ years) was added to the primary and secondary analyses. Although this increased the power to detect a difference in step-level change and change in trend, the pre-implementation modelled trend for 16-17 year olds was dominated by the $25+$ age group and thus proved a poor fit despite no evidence for a significant difference in the pre-intervention slope across the three groups for either smoking status, ever smoking status, or attempts to quit smoking ( $p=0.660$ to 0.875 ). Thus, the decision was made to include the results from this comparison only as supplementary material. Additional file 1: Tables S1-S5 give the results for those aged $25+$ relative to $16-17$ year olds and mirror Tables 1, 2, 3, 4, and 5 for 18-24 year olds relative to $16-17$ year olds.

Finally, additional sensitivity analyses were run following reviewer comments which (1) adjusted for longerterm step-level effects for the two policies occurring closest in time to the increase in age-of-sale: the introduction of a ban in enclosed public spaces and the pictorial health warnings on product packaging (long-term step-level effects were not assessed for the other policies due to model overparameterisation and lack of power) and (2) adjusted for self-reported weekly spend on tobacco. See $[38,39]$ for a detailed introduction to Kalman filtering. Additional file 1: Table S8 gives the results from these analyses. Findings were similar as those for the pre-planned primary analysis.

\section{Results}

Data were collected on 252,601 adults aged 16+ between November 2006 and September 2018. Of these, 2.06\% (95\% CI 2.01 to 2.12 ) were aged $16-17,12.19 \%$ (95\% CI 
Table 1 Descriptive statistics of the sample overall and as a function of the two age groups of interest (16-17 year olds and 18-24 year olds)

\begin{tabular}{|c|c|c|c|}
\hline & $\begin{array}{l}\text { Overall }(n=252,601) \\
\text { Unweighted, } \%(n) \\
\text { Weighted, \% (n) }\end{array}$ & $\begin{array}{l}\text { 16-17 year olds }(n=5190) \\
\text { Unweighted, \% ( } n) \\
\text { Weighted, \% (n) }\end{array}$ & $\begin{array}{l}\text { 18-24 year olds }(n=30,681) \\
\text { Unweighted, \% (n) } \\
\text { Weighted, \% (n) }\end{array}$ \\
\hline \multicolumn{4}{|l|}{ Gender } \\
\hline \multirow[t]{2}{*}{ Female } & $51.64(130,434)$ & $42.91(2227)^{a}$ & $47.35(14,526)^{b}$ \\
\hline & $51.20(129,327)$ & 44.96 (2599) & $49.21(15,839)$ \\
\hline \multirow[t]{2}{*}{ Other } & $48.36(122,167)$ & $57.09(2962)$ & $52.65(16,155)$ \\
\hline & $48.80(123,274)$ & 55.04 (3182) & $50.79(16,349)$ \\
\hline \multicolumn{4}{|l|}{ Social grade } \\
\hline \multirow[t]{2}{*}{$A B C 1$} & $60.72(178,191)$ & $64.89(3369)^{\mathrm{a}}$ & $67.06(20,576)^{b}$ \\
\hline & $76.57(193,419)$ & 71.06 (4108) & $71.19(22,916)$ \\
\hline \multirow[t]{2}{*}{ C2DE } & $29.46(74,410)$ & 35.09 (1821) & $32.94(10,105)$ \\
\hline & $23.43(59,183)$ & 28.94 (16773) & 28.81 (9272) \\
\hline \multirow[t]{2}{*}{ Current smoker } & $21.33(53,831)$ & $15.59(809)^{\mathrm{a}}$ & $28.73(8808)^{b}$ \\
\hline & $20.58(51,957)$ & 15.54 (898) & 27.91 (8975) \\
\hline \multirow[t]{2}{*}{ Ever smoker } & $37.66(95,060)$ & $17.81(924)^{a}$ & $34.07(10,443)^{b}$ \\
\hline & $36.68(92,577)$ & $17.87(1033)$ & $33.30(10,711)$ \\
\hline \multirow[t]{2}{*}{ Quit attempt ${ }^{*}$} & $35.87(20,238)$ & $44.38(379)^{\mathrm{a}}$ & $39.91(3694)^{b}$ \\
\hline & $36.15(19,877)$ & $43.94(420)$ & 40.32 (3822) \\
\hline
\end{tabular}

${ }^{¥}$ Among past-year smokers; according to chi-squared analyses, superscript a and $\mathrm{b}$ differ $p<0.001$

12.06 to 12.31$)$ were aged $18-24$, and $85.75 \%(95 \% \mathrm{CI}$ 85.62 to 85.90$)$ were aged $25+$ years. Figures 1,2 , and 3 show the prevalence of current smoking, ever smoking, and quit attempts over time in these three age groups.

Table 1 gives descriptive statistics for the sample as a whole and as function of the two age groups of interest from the pre-registered analysis (results for those aged 25+ can be found in Additional file 1: Table S1-S5 and summarised under unplanned analyses). Compared with the group aged 18-24 years, 16-17 year olds reported lower prevalence of current smoking and ever smoking and (among past-year smokers) higher prevalence of quit attempts.

\section{Primary analysis_difference-in-differences}

Table 2 shows the prevalence of current smoking, ever smoking, and quit attempts among past-year smokers before and after the increase in age-of-sale as a function of age. Table 3 shows the results of the primary analysis.

Following the rise in age-of-sale, there were no significant step-level changes in either current smoking or ever smoking. However, for ever smoking, a greater declining trend

Table 2 Prevalence of current smoking, ever smoking, and quit attempts among past-year smokers before and after the increase in age-of-sale

16-17 year olds ( $n=455$ before, $n=4735$ after), \% ( $n$ )

$18-24$ year olds ( $n=2186$ before, $n=28,495$ after), $\%(n)$

Current smoker

$\begin{array}{llr}\text { Before } & 23.74(108) & 37.42(818) \\ \text { After } & 14.80(701) & 28.07(7990)\end{array}$

Ever smoker

$\begin{array}{lcc}\text { Before } & 26.59(334) & 43.37(1238) \\ \text { After } & 16.96(803) & 33.35(9495) \\ \text { Quit attempt } & \\ \text { Before } & & 50.28(443) \\ \text { After } & 63.25(74) & 38.82(3251)\end{array}$


Table 3 Primary analysis — results of the GAM analyses fitting linear trends to current smoking status, ever smoking status, and quit attempts among past-year smokers (16-17 versus 18-24 year olds)

\begin{tabular}{|c|c|c|c|c|c|c|c|c|c|c|}
\hline & \multicolumn{5}{|c|}{ Unadjusted } & \multicolumn{5}{|c|}{$\begin{array}{l}\text { Adjusted for sex and social grade and } \\
\text { population-level policies }\end{array}$} \\
\hline & \multirow[t]{2}{*}{ OR } & \multicolumn{2}{|l|}{$95 \% \mathrm{Cl}$} & \multirow[t]{2}{*}{$p$} & \multirow[t]{2}{*}{$\mathrm{BFs}$} & \multirow[t]{2}{*}{$\overline{\mathrm{OR}}$} & \multicolumn{2}{|l|}{$95 \% \mathrm{Cl}$} & \multirow[t]{2}{*}{$p$} & \multirow[t]{2}{*}{ BFs } \\
\hline & & Lower & Upper & & & & Lower & Upper & & \\
\hline \multicolumn{11}{|l|}{ Current smoking } \\
\hline Trend & 0.982 & 0.956 & 1.008 & 0.179 & & 0.979 & 0.954 & 1.006 & 0.127 & \\
\hline Level & 0.903 & 0.670 & 1.218 & 0.504 & & 0.807 & 0.456 & 1.426 & 0.460 & \\
\hline Change in slope & 1.012 & 0.985 & 1.039 & 0.389 & & 1.012 & 0.986 & 1.041 & 0.364 & \\
\hline Age (16-17 ref) & 1.922 & 1.523 & 2.426 & $<0.001$ & & 1.953 & 1.542 & 2.475 & $<0.001$ & \\
\hline Level × age & 1.113 & 0.838 & 1.378 & 0.458 & 0.80 & 1.103 & 0.827 & 1.472 & 0.504 & 0.75 \\
\hline Slope $\times$ age & 1.001 & 0.999 & 1.004 & 0.233 & 1.22 & 1.002 & 0.999 & 1.004 & 0.141 & 2.10 \\
\hline \multicolumn{11}{|l|}{ Ever smoking } \\
\hline Trend & 0.981 & 0.955 & 1.007 & 0.145 & & 0.978 & 0.953 & 1.004 & 0.103 & \\
\hline Level & 0.950 & 0.713 & 1.267 & 0.727 & & 0.899 & 0.520 & 1.552 & 0.702 & \\
\hline Change in slope & 1.012 & 0.986 & 1.039 & 0.358 & & 1.012 & 0.985 & 1.040 & 0.374 & \\
\hline Age (16-17 ref) & 2.116 & 1.690 & 2.649 & $<0.001$ & & 2.139 & 1.703 & 2.686 & $<0.001$ & \\
\hline Level × age & 1.044 & 0.785 & 1.371 & 0.755 & 0.52 & 1.036 & 0.786 & 1.366 & 0.803 & 0.50 \\
\hline Slope $\times$ age & 1.002 & 1.000 & 1.005 & 0.040 & 2.10 & 1.003 & 1.000 & 1.005 & 0.019 & 4.20 \\
\hline Trend after 16-17 & 0.993 & 0.942 & 1.046 & & & 0.990 & 0.939 & 1.044 & & \\
\hline Trend after 18-24 & 0.995 & 0.942 & 1.052 & & & 0.993 & 0.939 & 1.049 & & \\
\hline \multicolumn{11}{|l|}{ Quit attempts } \\
\hline Trend & 0.985 & 0.945 & 1.027 & 0.485 & & 0.984 & 0.944 & 1.027 & 0.464 & \\
\hline Level & 0.529 & 0.322 & 0.902 & 0.019 & & 0.311 & 0.117 & 0.825 & 0.019 & \\
\hline Change in slope & 1.011 & 0.970 & 1.055 & 0.598 & & 1.014 & 0.971 & 1.058 & 0.526 & \\
\hline Age (16-17 ref) & 0.587 & 0.394 & 0.874 & 0.009 & & 0.585 & 0.393 & 0.872 & 0.009 & \\
\hline Level × age & 1.770 & 1.081 & 2.899 & 0.023 & 5.68 & 1.760 & 1.075 & 2.884 & 0.025 & 5.49 \\
\hline Slope $\times$ age & 0.998 & 0.994 & 1.003 & 0.440 & 0.71 & 0.998 & 0.994 & 1.003 & 0.460 & 0.71 \\
\hline Level 16-17 & 0.529 & 0.322 & 0.902 & & & 0.311 & 0.117 & 0.825 & & \\
\hline Level 18-24 & 0.936 & 0.348 & 2.615 & & & 0.547 & 0.126 & 2.379 & & \\
\hline
\end{tabular}

BFs Bayes factors; the ORs representing the main effects for level and slope (i.e. $\beta_{3}$ level and $\beta_{4}$ slope) can be interpreted as the effect among $16-17$ year olds, while the effect among the comparison groups is calculated as the main effects multiplied by the ORs for the interactions (i.e. $\beta_{3}$ level $\times\left(\beta_{5}\right.$ level $l_{t} \times$ age) and $\beta_{4}$ slope $\times\left(\beta_{6}\right.$ slope $\times$ age $\left.)\right)$

Table 4 AIC values for the post-age-of-sale implantation trend analysis (16-17 versus and 18-24 year olds)

\begin{tabular}{|c|c|c|c|c|c|c|}
\hline & \multicolumn{2}{|l|}{ Smoking } & \multicolumn{2}{|c|}{ Ever smoking } & \multicolumn{2}{|c|}{$\begin{array}{l}\text { Quit attempts among } \\
\text { past-year smokers }\end{array}$} \\
\hline & $\overline{16-17}$ & $18-24$ & $16-17$ & $18-24$ & $16-17$ & $18-24$ \\
\hline Linear trend & 25,407 & 136,031 & 24,867 & 133,131 & 3653 & 39,621 \\
\hline Quadratic trend & 25,426 & 136,025 & 24,879 & 133,127 & 3653 & 39,621 \\
\hline Cubic trend & 25,428 & 136,026 & 24,880 & 133,127 & 3653 & 39,621 \\
\hline Linear best fitting segmented & 25,408 & 136,028 & 24,868 & 133,129 & 3655 & 39,623 \\
\hline Quadratic best fitting segmented & 25,413 & 136,027 & 24,876 & 133,129 & 3655 & 39,623 \\
\hline Cubic best fitting segmented & 25,413 & 136,028 & 24,875 & 133,129 & 3655 & 39,634 \\
\hline
\end{tabular}


Table 5 Secondary analysis—results of the best fitting GAMM post-age-of-sale trend analysis

\begin{tabular}{|c|c|c|c|c|c|c|c|c|}
\hline & \multicolumn{4}{|c|}{ Unadjusted } & \multicolumn{4}{|c|}{$\begin{array}{l}\text { Adjusted for sex and social grade and } \\
\text { population-level policies }\end{array}$} \\
\hline & \multirow[t]{2}{*}{$\mathrm{OR}$} & \multicolumn{2}{|l|}{$95 \% \mathrm{Cl}$} & \multirow[t]{2}{*}{$p$} & \multirow[t]{2}{*}{ OR } & \multicolumn{2}{|l|}{$95 \% \mathrm{Cl}$} & \multirow[t]{2}{*}{$p$} \\
\hline & & Lower & Upper & & & Lower & Upper & \\
\hline \multicolumn{9}{|l|}{ Current smoking 16-17 } \\
\hline Trend & 0.996 & 0.928 & 1.070 & 0.919 & 1.005 & 0.935 & 1.081 & 0.883 \\
\hline Level & 0.841 & 0.537 & 1.319 & 0.452 & 0.739 & 0.456 & 1.199 & 0.221 \\
\hline Change in slope & 0.997 & 0.929 & 1.071 & 0.936 & 0.988 & 0.919 & 1.062 & 0.743 \\
\hline \multicolumn{9}{|l|}{ Current smoking $18-24$} \\
\hline Trend & 0.979 & 0.951 & 1.007 & 0.144 & 0.975 & 0.947 & 1.003 & 0.082 \\
\hline Level & 1.073 & 0.887 & 1.297 & 0.468 & 1.119 & 0.919 & 1.362 & 0.264 \\
\hline Change in slope & 1.014 & 0.985 & 1.004 & 0.336 & 1.017 & 0.988 & 1.047 & 0.253 \\
\hline Change in slope $\wedge 2$ & 1.000 & 1.000 & 1.000 & 0.114 & 1.000 & 1.000 & 1.000 & 0.003 \\
\hline \multicolumn{9}{|l|}{ Ever smoking 16-17 } \\
\hline Trend & 0.989 & 0.922 & 1.061 & 0.756 & 0.996 & 0.928 & 1.070 & 0.914 \\
\hline Level & 0.915 & 0.588 & 1.423 & 0.694 & 0.844 & 0.526 & 1.356 & 0.484 \\
\hline Change in slope & 1.004 & 0.936 & 1.077 & 0.912 & 0.997 & 0.928 & 1.070 & 0.928 \\
\hline \multicolumn{9}{|l|}{ Ever smoking 18-24 } \\
\hline Trend & 0.979 & 0.952 & 1.007 & 0.133 & 0.974 & 0.947 & 1.002 & 0.073 \\
\hline Level & 1.030 & 0.857 & 1.240 & 0.751 & 1.059 & 0.874 & 1.284 & 0.556 \\
\hline Change in slope & 1.016 & 0.988 & 1.045 & 0.278 & 1.019 & 0.990 & 1.048 & 0.196 \\
\hline Change in slope $\wedge 2$ & 1.000 & 1.000 & 1.000 & 0.377 & 1.000 & 1.000 & 1.000 & 0.029 \\
\hline \multicolumn{9}{|l|}{ Quit attempts 16-17 } \\
\hline Trend & 1.019 & 0.902 & 1.151 & 0.766 & 1.028 & 0.907 & 1.164 & 0.666 \\
\hline Level & 0.451 & 0.204 & 1.000 & 0.050 & 0.448 & 0.193 & 1.036 & 0.061 \\
\hline Change in slope & 0.978 & 0.867 & 1.105 & 0.723 & 0.969 & 0.855 & 1.098 & 0.623 \\
\hline \multicolumn{9}{|l|}{ Change in slope 18-24 } \\
\hline Trend & 0.982 & 0.939 & 1.026 & 0.412 & 0.980 & 0.937 & 1.024 & 0.364 \\
\hline Level & 0.975 & 0.737 & 1.290 & 0.859 & 0.982 & 0.735 & 1.311 & 0.901 \\
\hline Change in slope & 1.013 & 0.969 & 1.059 & 0.561 & 1.016 & 0.971 & 1.062 & 0.497 \\
\hline
\end{tabular}

was found among 16-17 year olds relative to 18-24 year olds following the increase in age-of-sale. For every postimplementation month, the odds of ever smoking decreased by $1 \%$ for those aged $16-17$ and $0.7 \%$ for those aged $18-24$ (OR 0.990 versus $0.993, p=0.019$ ). For quit attempts only, there was also a significantly greater step-level decline among 16-17 year olds relative to $18-24$ year olds after the increase in age-of-sale. The overall odds of a quit attempt decreased by $69 \%$ among those aged $16-17$ and $45 \%$ among those aged $18-24$ (OR 0.311 versus $0.547, p=$ $0.025)$ following the increase in age-of-sale implementation. Bayes factors indicated that the data were largely insensitive to detect other associations. Additional file 1: Fig. S1 shows the results of the fitted GAM models.

\section{Secondary analysis-trend analysis}

Whereas the trends for current smoking and ever smoking post-increase in age-of-sale were linear for
16-17 year olds, they were better explained by a quadratic function (slowing declines) for 18-24 year olds. Trends in quit attempts post-increase in age-ofsale followed a linear decline across both age groups (see Tables 4 and 5).

\section{Sensitivity analyses-comparison with 18-21 and 22-24 year olds}

As for the comparison with 18-24 year olds, there was a significantly greater declining trend in ever smoking among 16-17 year olds following the increase in age-ofsale compared with 22-24 year olds but not relative to 18-21 year olds (Additional file 1: Table S6-S7). As before, a greater step-level decline in quit attempts was found for 16-17 year olds versus 18-21 year olds (Additional file 1: Table S6) and 22-24 year olds (Additional file 1: Table S7). All other associations were non-significant. 


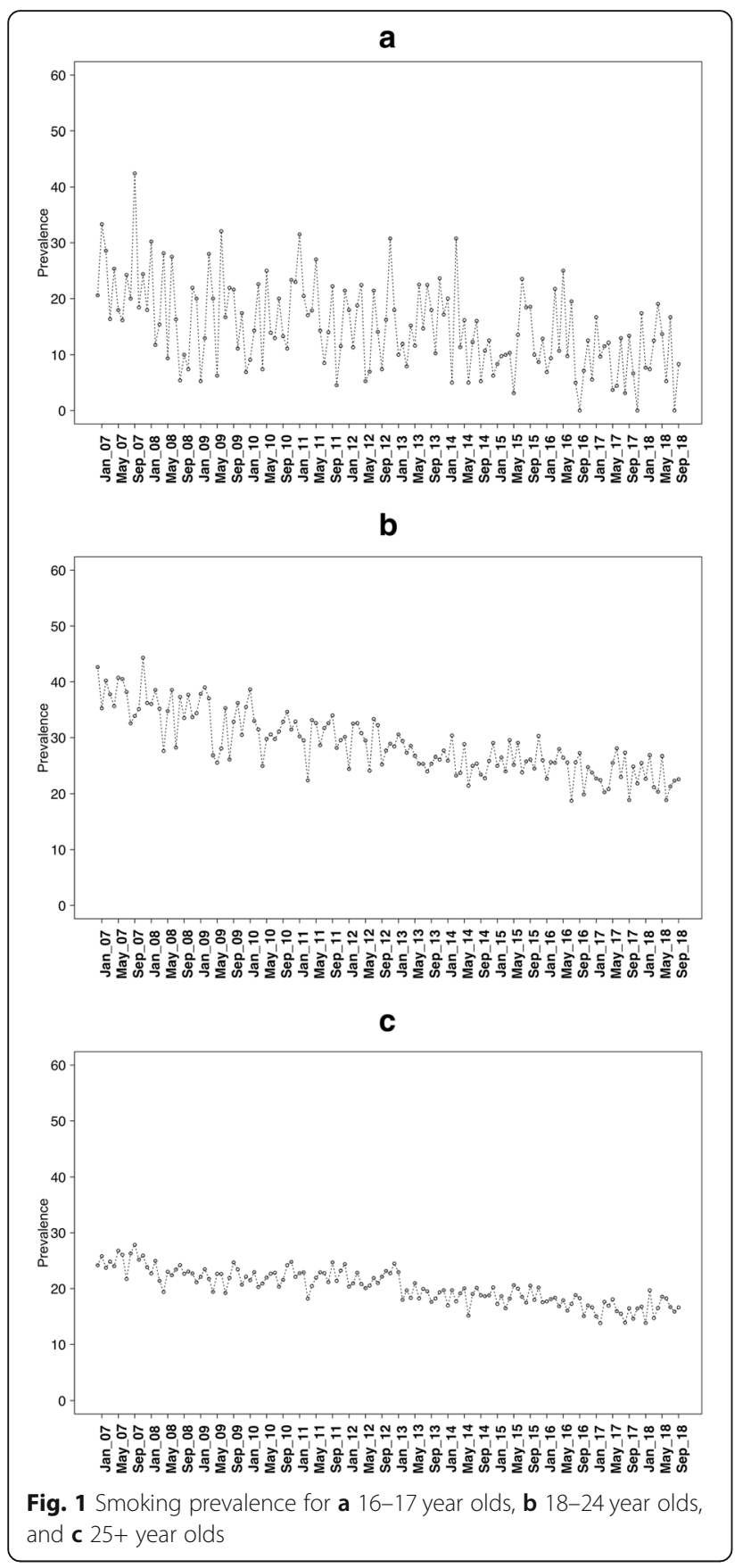

\section{Unplanned analyses-comparison with 25+ year olds}

Additional file 1: Table S1 gives descriptive statistics for the sample as a whole and as function of the two age groups of interest (16-17 versus 25+ year olds). Additional file 1: Table S2 shows the prevalence of smoking, ever smoking, and quit attempts among pastyear smokers before and after the increase in age-of-sale as a function of age, while Additional file 1: Table S3 shows the results of the primary analysis.

Following the increase in age-of-sale, there was a steplevel decline in current smoking across both age groups

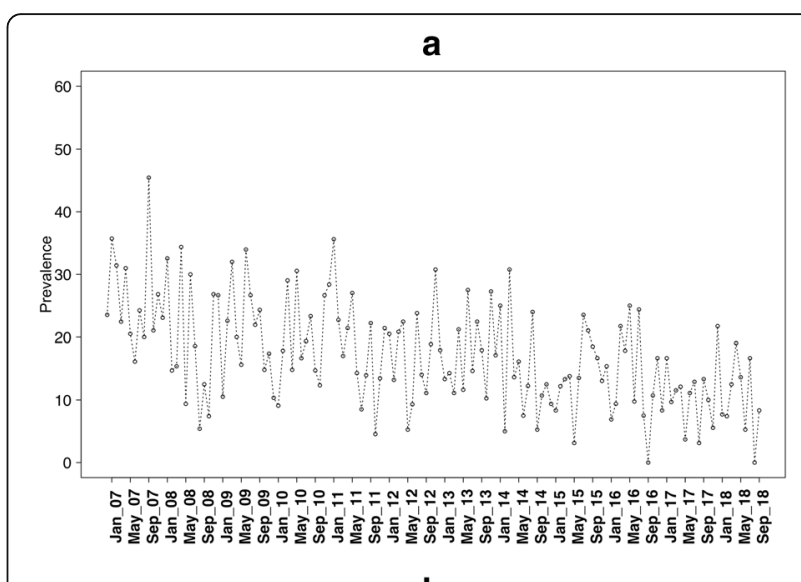

b
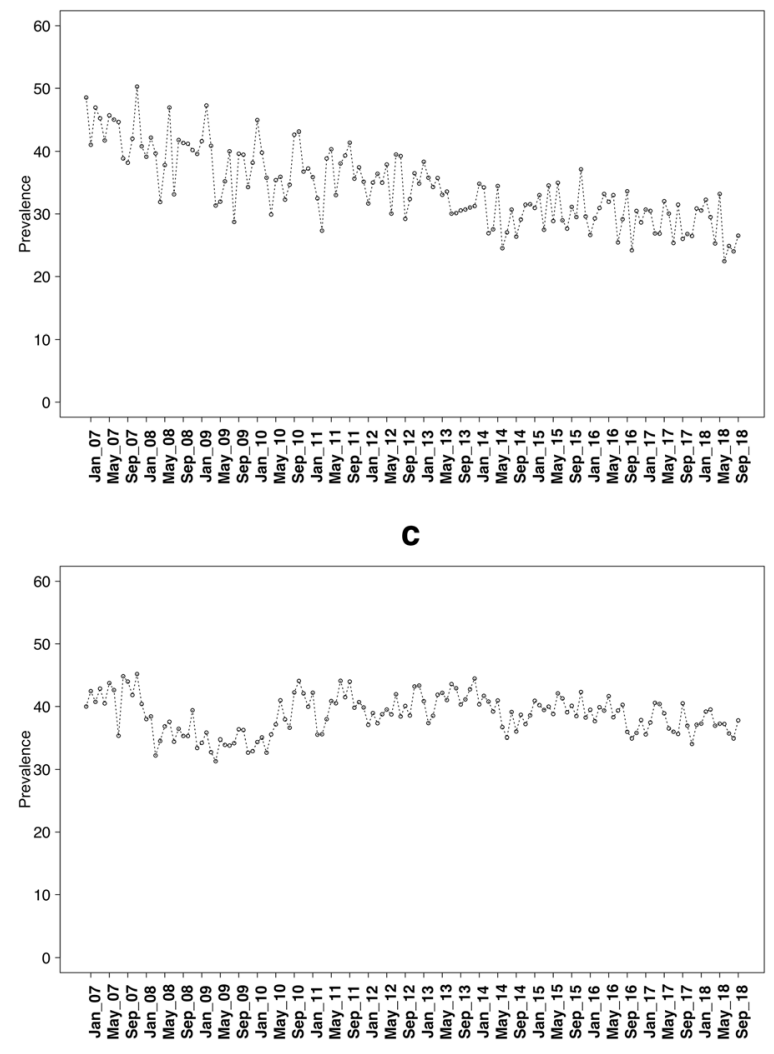

Fig. 2 Ever smoking prevalence for a 16-17 year olds, b 18-24 year olds, and c $25+$ year olds

(OR 0.756, $p=0.047$ ) but no significant step-level change in ever smoking (OR 0.847, $p=0.216$ ). This was then followed by a larger declining trend in current smoking among 16-17 year olds relative to $25+$ year olds (OR 0.994 versus $0.998, p=0.002$ ). There was also a decline in ever smoking among 16-17 year olds over time but an increase among 25+ year olds (OR 0.993 versus $1.001, p<0.001)$. In contrast, although the probability of making a quit attempt remained higher among 16-17 year olds across the study period, there was a significantly greater step-level decline relative to $25+$ year olds 


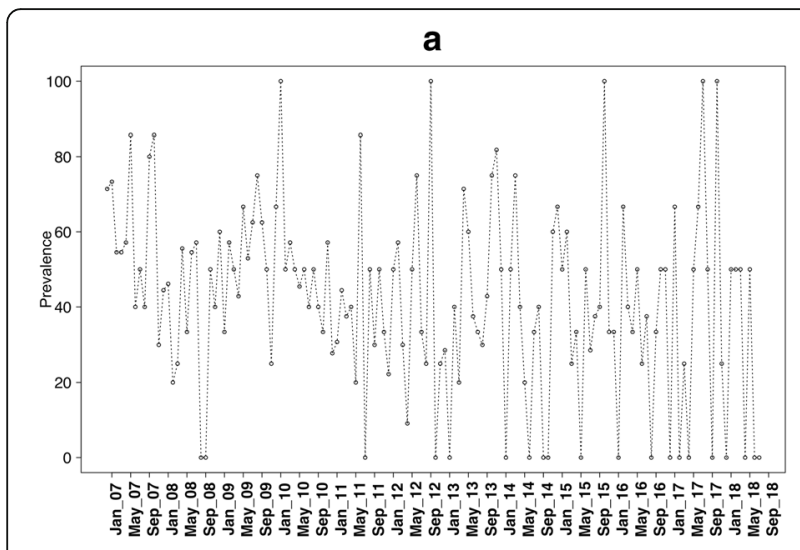

b

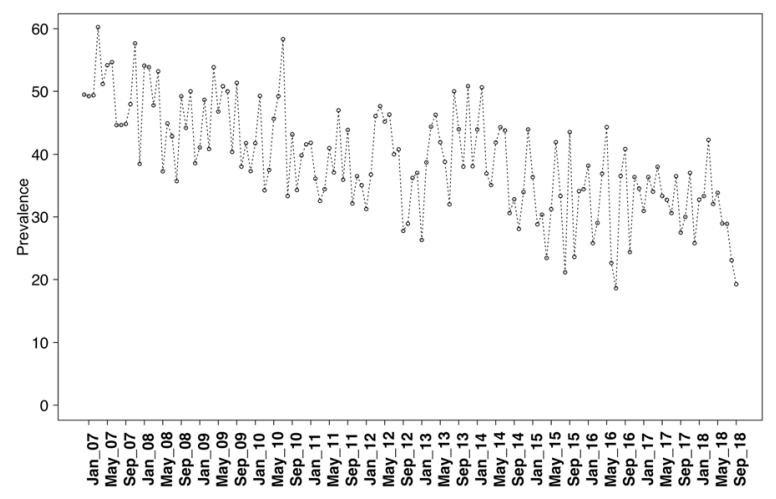

C

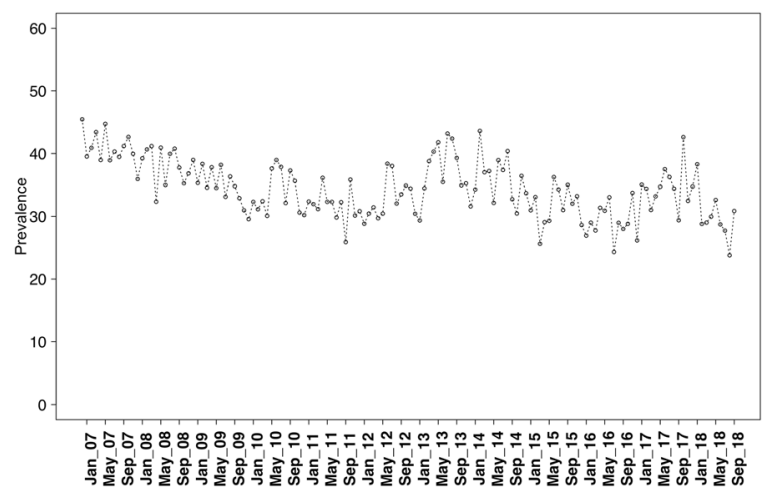

Fig. 3 Prevalence of quit attempts for a 16-17 year olds, b 18-24 year olds, and c $25+$ year olds

after the increase in age-of-sale. Bayes factors indicated that the data were largely insensitive to detect other associations. There was evidence for the null hypothesis of no difference between age groups in a step-level change for ever smoking. Additional file 1: Fig. 1 shows the results of the fitted GAM models.

The post-increase in age-of-sale trends for smoking, ever smoking, and quit attempts was linear for 16-17 year olds and 25+ year olds Additional file 1: Table S4-S5.

\section{Discussion}

\section{Statement of principal findings}

To our knowledge, this is the first attempt to examine the long-term impact of the increase in age-of-sale of cigarettes from 16 to 18 years in England on smoking behaviour. The results indicate that although ever smoking declined across age groups in the decade following the increase in age-of-sale, the decline was greater among 16-17 year olds compared with 18-24 year olds. In contrast, a greater step-level decline in quit attempts was also found among 16-17 year olds. These findings were largely corroborated in the comparison with those aged $25+$, where a greater post-implementation decline was also found in current smoking among 16-17 year olds compared with $25+$ year olds.

\section{Comparison with previous studies}

These findings are consistent with previous studies in England showing a short-term positive impact of increasing the legal age-of-sale [2, 6]. In the study by Fidler and West [2], the odds of smoking were 36\% higher for those aged $18+$ compared to 16 to 17 year olds over the 18-month period following the increase in age-of-sale. In this study, for every post-implementation month, the odds of ever smoking were around $0.3 \%$ lower for those aged 16-17 compared to 18-24 year olds and $0.8 \%$ lower compared to those aged $25+$, thus a difference in odds of about $5.4 \%$ and $14.4 \%$ over the same time period as Fidler and West. This would suggest a significant but smaller impact long term. The larger decline in quit attempts among 16-17 year olds than 1824 year olds may reflect a temporary increase in quitting activity occurring just before the increase in age-of-sale as a consequence of 'smokefree' legislation which was implemented in July 2007 [18]. Alternatively, it could reflect a change in the characteristics of smokers over time (e.g. they become more dependent and less motivated to quit). Previous studies have found that motivation to quit is a major predictor of quit attempts at the individual and population level $[40,41]$. However, there is little support for the 'hardening hypothesis' [42]. Although motivation to quit appears to have declined among smokers, nicotine dependence is decreasing [43].

\section{Strengths and weaknesses of the study}

There are several limitations of the current study which need to be considered. First, it was not possible to obtain saliva samples to confirm smoking status, and therefore, misreporting may bias results. However, there was no reason to believe that misreporting would vary over time or between age groups. Secondly, due to low power, owing to the small number of waves of data collection before the age-of-sale was implemented, it was not possible to model the pre-implementation trend separately 
among the age groups or to stratify findings according to socio-demographic characteristics. Thus, we cannot address questions such as whether the smoking behaviour of those in routine and manual social grades was differentially affected relative to those in higher social grades. It is conceivable that those in more disadvantaged groups were less affected by the increase in the age-of-sale because they have greater access to cigarettes from social and family networks and through illicit sources [44]. Thirdly, Bayes factors suggested that for the primary comparison, our study was insensitive to detect a difference in smoking prevalence following the increase in age-of-sale between those aged 16-17 and those aged $18-24$. This is likely also due to short preimplementation trend, which meant that the study was not powered to detect the hypothesised effects. Fourthly, although we adjusted for other population-level policies and tobacco control mass media spend, we only considered temporary 1-month pulse effects and step level changes for the two policies occuring closest in time. It is possible that any impact may have been in a different form, e.g. a change in trend. This warrants further investigation but was beyond the scope of the current study and would have required substantially more power. Fifthly, although we a priori decided on the covariates to adjust for in the current study in order to prevent overparameterisation, there are several unadjusted confounders that should be considered. For example, although cost of cigarettes increases linearity over time and is therefore accounted for by the underlying linear trend, and there does not appear to be an association between the affordability of cigarettes and quitting activity [14], tax increases have been shown to impact on youth smoking rates [33]. However, the effectiveness of tax increases is often undermined by the use of 'undershifting' (absorbing the tax increases) by tobacco companies [45]. Finally, this study's measure of socio-economic status, social grade, has limitations for young adults as it is based on the occupation of the chief income earner [15, 46]. However, to prevent overparameterisation and multicollinearity, it was agreed a priori that we should only adjust for one socio-economic measure. This measure in the STS has been found to have the strongest independent association with smoking status among people in England while adjusting for age [47]. The important feature of covariates for trend analyses is that they pick up any systematic changes in a population over time, rather than their categorisation accuracy.

\section{Implications}

The current study adds to previous research that has documented an association between the change in age-of-sale and a drop in youth smoking $[2,6]$, and supports the view that such legislation may be an effective policy for tobacco control. Given the potential impact on the future health of a generation of young adults, it raises the question as to whether we should increase the legal age-of-sale even further to 21 years. Central to the original argument for increasing the age-of-sale from 16 to 18 was that the majority of smokers had tried their first cigarette by this age [48]. However, smokers' transition to regular daily use generally occurs between 18 and 21 years of age [49]. Tobacco companies have also long viewed young adults aged 18 to 21 as a key target market group [50]. A hypothetical health policy model in which the tobacco age-of-sale was increased to 21 years has projected that youth smoking prevalence could be expected to drop by over $10 \%$ within 7 years [51]. Currently, the WHO Framework Convention on Tobacco Control (FCTC) specifically supports measures to prohibit the sales of tobacco products to those classed as 'minors' as set by national law or the age of 18 , but also encourages parties to the FCTC to implement measures beyond those required by the convention [52].

\section{Conclusion}

In conclusion, the increase in legal age-of-sale of cigarettes from 16 to 18 years in England was associated with a greater long-term ( $\geq 10$ year) decline in ever smoking among those aged 16-17 compared with those aged 18-24 years. Data on current smoking and quit attempts were inconclusive for this comparison.

\section{Supplementary information}

Supplementary information accompanies this paper at https://doi.org/10. 1186/s12916-020-01541-W.

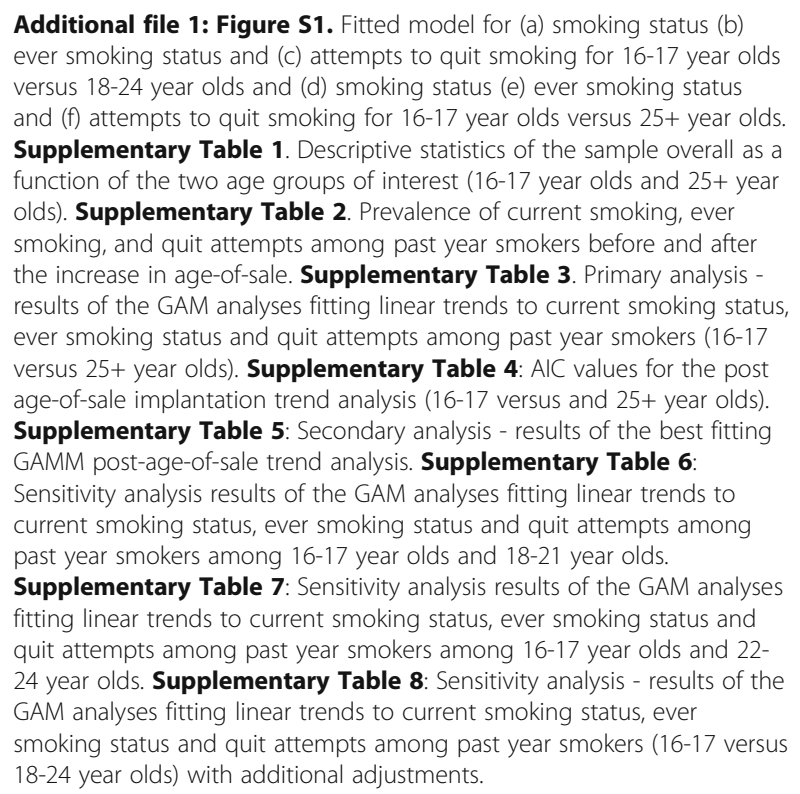

Abbreviations

GAMs: Generalised Additive Models; STS: Smoking Toolkit Study 


\section{Acknowledgements}

We gratefully acknowledge our funders.

\section{Authors' contributions}

All authors read and approved the final manuscript. EB, JB, SJ, and LS designed the study. EB wrote the first draft and conducted the analyses. All authors commented on this draft and contributed to the final version. EB had full access to all of the data (including statistical reports and tables) in the study and can take responsibility for the integrity of the data and the accuracy of the data analysis. EB is the study guarantor. The corresponding author attests that all listed authors meet authorship criteria and that no others meeting the criteria have been omitted.

\section{Funding}

The Smoking Toolkit Study is currently primarily funded by Cancer Research UK (C1417/A14135) and has previously also been funded by Pfizer, GSK, and the Department of Health. No funders had any involvement in the design of the study, the analysis or interpretation of the data, the writing of the report, or the decision to submit the paper for publication. EB, RW, and JB are funded by Cancer Research UK (C1417/A14135). The views expressed are those of the authors(s) and not necessarily those of CRUK. Authors are members of the UK Prevention Research Partnership, an initiative funded by UK Research and Innovation Councils, the Department of Health and Social Care (England) and the UK devolved administrations, and leading health research charities. No funders had any involvement in the design of the study, the analysis or interpretation of the data, the writing of the report, or the decision to submit the paper for publication.

\section{Availability of data and materials}

For access to the Smoking Toolkit Study, please contact JB or EB (jamie. brown@ucl.ac.uk and e.beard@ucl.ac.uk).The R code for this paper is available on request from $\mathrm{EB}$.

\section{Ethics approval and consent to participate}

Ethical approval for the Smoking Toolkit Study was granted by the UCL ethics committee (ID 0498/001). The data are not collected by UCL and are anonymised when received by $\mathrm{UCL}$.

\section{Consent for publication}

Participants provided full informed consent.

\section{Competing interests}

All authors have completed the ICMJE uniform disclosure form at www. icmje.org/coi_disclosure.pdf (available on request from the corresponding author) and declare the following: RW and LS undertake consultancy and research for and receive travel funds and hospitality from manufacturers of smoking cessation medications. EB, JB, and LS have received unrestricted research funding from Pfizer. The other authors declare that they have no competing interests.

\section{Author details}

'Department of Behavioural Science and Health, University College London, 1-19 Torrington Place, London, UK. ${ }^{2}$ Action on Smoking and Health (ASH), London, UK.

Received: 18 October 2019 Accepted: 20 February 2020 Published online: 08 April 2020

\section{References}

1. Filippidis FT, Agaku IT, Vardavas Cl. The association between peer, parental influence and tobacco product features and earlier age of onset of regular smoking among adults in 27 European countries. Eur J Pub Health. 2015; 25(5):814-8

2. Fidler JA, West R. Changes in smoking prevalence in 16-17-year-old versus older adults following a rise in legal age of sale: findings from an English population study. Addiction. 2010;105(11):1984-8.

3. Hopkinson NS. Keep out of reach of children - the case for increasing the legal age for tobacco purchase to 21. BMJ. 2019;364:11330.

4. Winickoff JP. Maximizing the impact of Tobacco 21 laws across the United States. Am J Public Health. 2018;108(5):594-5.
5. Friedman AS, Buckell J, Sindelar JL. Tobacco-21 laws and young adult smoking: quasi-experimental evidence. Addiction. 2019;114(10):1816-1823.

6. Millett C, Lee JT, Gibbons DC, Glantz SA. Increasing the age for the legal purchase of tobacco in England: impacts on socio-economic disparities in youth smoking. Thorax. 2011;66(10):862-5.

7. Institute of Medicine. Public health implications of raising the minimum age of legal access to tobacco products.; 2015.

8. Sundh $M$, Hagquist $C$. Does a minimum-age law for purchasing tobacco make any difference? Swedish experiences over eight years. Eur J Pub Health. 2007;17(2):171-7.

9. Kuipers MA, Brandhof SD, Monshouwer K, Stronks K, Kunst AE. Impact of laws restricting the sale of tobacco to minors on adolescent smoking and perceived obtainability of cigarettes: an intervention-control pre-post study of 19 European Union countries. Addiction (Abingdon). 2017;112(2):320-9.

10. Jason LA, Ji PY, Anes MD, Birkhead SH. Active enforcement of cigarette control laws in the prevention of cigarette sales to minors. JAMA. 1991; 266(22):3159-61.

11. Rimpela AH, Rainio SU. The effectiveness of tobacco sales ban to minors: the case of Finland. Tob Control. 2004;13(2):167-74.

12. Callaghan RC, Sanches M, Gatley J, Cunningham JK, Chaiton MO, Schwartz $R$, et al. Impacts of Canada's minimum age for tobacco sales (MATS) laws on youth smoking behaviour, 2000-2014. Tob Control. 2018;27(e2):e105-e11.

13. Beard E, West R, Michie S, Brown J. Association between electronic cigarette use and changes in quit attempts, success of quit attempts, use of smoking cessation pharmacotherapy, and use of stop smoking services in England: time-series analysis of population trends. BMJ. 2016;354:14645.

14. Beard E, West R, Michie S, Brown J. Association of prevalence of electronic cigarette use with smoking cessation and cigarette consumption in England: a time series analysis between 2006 and 2017. Addiction.n/a(n/a),

15. Fidler JA, Shahab L, West O, Jarvis MJ, McEwen A, Stapleton JA, et al. The smoking toolkit study': a national study of smoking and smoking cessation in England. BMC Public Health. 2011;11(1):479.

16. Jackson SE, Beard E, Kujawski B, Sunyer E, Michie S, Shahab L, et al. Comparison of trends in self-reported cigarette consumption and sales in England, 2011 to 2018. JAMA Network Open. 2019;2(8):e1910161-e.

17. Collis D. Social grade: a classification tool - Bite sized through piece 2009. Available from: https://www.ipsos-mori.com/DownloadPublication/1285_ MediaCT_thoughtpiece_Social_Grade_July09_V3_WEB.pdf.

18. Hackshaw L, McEwen A, West R, Bauld L. Quit attempts in response to smoke-free legislation in England. Tob Control. 2010;19(2):160-4.

19. Hammond D. Health warning messages on tobacco products: a review. Tob Control. 2011;20(5):327-37.

20. Beard E, Michie S, Fidler J, West R. Use of nicotine replacement therapy in situations involving temporary abstinence from smoking: a national survey of English smokers. Addict Behav. 2013;38(3):1876-9.

21. Kuipers MA, Beard E, Hitchman SC, Brown J, Stronks K, Kunst AE, West R. Impact on smoking of England's 2012 partial tobacco point of sale display ban: a repeated cross-sectional national study. Tobacco Control. 2017;26(2):141-148.

22. Health and Social Care Information Centre. NHS stop smoking services collection 2015. Available from: www.hscic.gov.uk/stopsmoking.

23. NICE. NICE guidelines [PH45]: Smoking: Harm reduction 2013. Available from: https://www.nice.org.uk/guidance/ph45.

24. Kuipers MA, Partos T, McNeill A, Beard E, Gilmore AB, West R, Brown J. Smokers' strategies across social grades to minimise the cost of smoking in a period with annual tax increases: evidence from a national survey in England. BMJ open. 2019;9(6):e026320.

25. White V, Webster B, Wakefield M. Do graphic health warning labels have an impact on adolescents' smoking-related beliefs and behaviours? Addiction. 2008;103(9):1562-71.

26. Beard E, Jackson SE, West R, Kuipers MA, Brown J. Population-level predictors of changes in success rates of smoking quit attempts in England: a time series analysis. Addiction. 2020;115(2);315-325.

27. Langley T, Szatkowski L, Lewis S, McNeill A, Gilmore AB, Salway R, et al. The freeze on mass media campaigns in England: a natural experiment of the impact of tobacco control campaigns on quitting behaviour. Addiction. 2014;109(6):995-1002.

28. Wakefield MA, Durkin S, Spittal MJ, Siahpush M, Scollo M, Simpson JA, et al. Impact of tobacco control policies and mass media campaigns on monthly adult smoking prevalence. Am J Public Health. 2008;98(8):1443-50.

29. Kotz D, West R. Explaining the social gradient in smoking cessation: it's not in the trying, but in the succeeding. Tob Control. 2009;18(1):43-6. 
30. Jackson SE, Smith C, Cheeseman H, West R, Brown J. Finding smoking hotspots: a cross-sectional survey of smoking patterns by housing tenure in England. Addiction. 2019;114(5):889-95.

31. Higgins ST, Kurti AN, Redner R, White TJ, Gaalema DE, Roberts ME, et al. A literature review on prevalence of gender differences and intersections with other vulnerabilities to tobacco use in the United States, 2004-2014. Prev Med. 2015;80:89-100.

32. Callison $\mathrm{K}$, Kaestner R. Do higher tobacco taxes reduce adult smoking? New evidence of the effect of recent cigarette tax increases on adult smoking. Econ Inq. 2014;52(1):155-72.

33. Chaloupka FJ, Yurekli A, Fong GT. Tobacco taxes as a tobacco control strategy. Tob Control. 2012;21(2):172-80.

34. Chaloupka FJ, Straif K, Leon ME. Effectiveness of tax and price policies in tobacco control. Tob Control. 2011;20(3):235-8.

35. Moritz S, Bartz-Beielstein T. imputeTS: time series missing value imputation in R. The R Journal. 2017;9(1):207-18.

36. Dienes Z. Using Bayes to get the most out of non-significant results. Front Psychol. 2014:5:781.

37. Von Elm E, Altman DG, Egger M, Pocock SJ, Gøtzsche PC, Vandenbroucke $J \mathrm{P}$, et al. The Strengthening the Reporting of Observational Studies in Epidemiology (STROBE) statement: guidelines for reporting observational studies. Prev Med. 2007:45(4):247-51.

38. Bishop $\mathrm{G}$, Welch $\mathrm{G}$. An introduction to the Kalman filter. Proc of SIGGRAPH, Course. 2001;8(27599-3175):59.

39. Harvey AC. Forecasting, structural time series models and the Kalman filter. Cambridge university press; 1990 .

40. Vangeli E, Stapleton J, Smit ES, Borland R, West R. Predictors of attempts to stop smoking and their success in adult general population samples: a systematic review. Addiction. 2011;106(12):2110-21.

41. Beard E, Jackson SE, West R, Kuipers MA, Brown J. Trends in attempts to quit smoking in England since 2007: A time series analysis of a range of population-level influences. Nicotine \& Tobacco Research; 2019.

42. Hughes J. The hardening hypothesis: is the ability to quit decreasing due to increasing nicotine dependence? Drug Alcohol Depend. 2011;117:111-7.

43. Garnett C, Tombor I, Beard E, Jackson SE, West R, Brown J. Changes in smoker characteristics in England between 2008 and 2017. Addiction; 2019.

44. Borland T, Amos A. An exploratory study of the perceived impact of raising the age of cigarette purchase on young smokers in Scotland. Public Health. 2009;123(10):673-9.

45. Hiscock R, Branston JR, McNeill A, Hitchman SC, Partos TR, Gilmore AB. Tobacco industry strategies undermine government tax policy: evidence from commercial data. Tob Control. 2018;27(5):488-97.

46. National Readership Survey. Social Grade Definitions and Discriminatory Power. Available from: http://www.nrs.co.uk/nrs-print/lifestyle-andclassification-data/social-grade/. Accessed Jan 2020.

47. Beard E, Brown J, Jackson SE, West R, Kock L, Boniface S, Shahab L. Independent associations between different measures of socioeconomic position and smoking status: A cross-sectional study of adults in England. Nicotine \& Tobacco Research; 2020

48. US Department of Health and Human Services. Preventing tobacco use among youth and young adults: a report of the Surgeon General; 2012.

49. Hammond D. Smoking behaviour among young adults: beyond youth prevention. Tob Control. 2005;14(3):181-5.

50. Ling PM, Glantz SA. Why and how the tobacco industry sells cigarettes to young adults: evidence from industry documents. Am J Public Health. 2002; 92(6):908-16.

51. Ahmad S, Billimek J. Limiting youth access to tobacco: comparing the long-term health impacts of increasing cigarette excise taxes and raising the legal smoking age to 21 in the United States. Health Policy. 2007:80(3):378-91.

52. Burci GL. World Health Organization (WHO): framework convention on tobacco control. Int Leg Mater. 2003;42(3):515-39.

\section{Publisher's Note}

Springer Nature remains neutral with regard to jurisdictional claims in published maps and institutional affiliations.

Ready to submit your research? Choose BMC and benefit from:

- fast, convenient online submission

- thorough peer review by experienced researchers in your field

- rapid publication on acceptance

- support for research data, including large and complex data types

- gold Open Access which fosters wider collaboration and increased citations

- maximum visibility for your research: over $100 \mathrm{M}$ website views per year

At BMC, research is always in progress.

Learn more biomedcentral.com/submissions 